\title{
Differential gene expression analysis by RNA-seq reveals the importance of actin cytoskeletal proteins in erythroleukemia cells
}

Vanessa Fernández-Calleja $^{1}{ }^{\text {， Pablo Hernández }}{ }^{1}$, Jorge B Schvartzman ${ }^{1}$, Mario García de Lacoba ${ }^{2}$, Dora B Krimer Corresp. 1

${ }^{1}$ Department of Cellular and Molecular Biology, Centro de Investigaciones Biológicas, Spanish National Research Council (CSIC), Madrid, Spain

2 Bioinformatics and Biostatistics Service, Centro de Investigaciones Biológicas, Spanish National Research Council (CSIC), Madrid, Spain

Corresponding Author: Dora B Krimer

Email address: dbkrimer@cib.csic.es

Development of drug resistance limits the effectiveness of anticancer treatments.

Understanding the molecular mechanisms triggering this event in tumor cells may lead to improved therapeutic strategies. Here we used RNA-seq to compare the transcriptomes of a murine erythroleukemia cell line (MEL) and a derived cell line with induced resistance to differentiation (MEL-R). RNA-seq analysis identified a total of 596 genes (BenjaminiHochberg adjusted $p$-value $<0.05$ ) that were differentially expressed by more than twofold, of which $81.5 \%$ (486/596) of genes were up-regulated in MEL cells and 110 upregulated in MEL-R cells. These observations revealed that for some genes the relative expression of mRNA amount in the MEL cell line has decreased as the cells acquired the resistant phenotype. Clustering analysis of a group of genes showing the highest differential expression allowed identification of a sub-group among genes up-regulated in MEL cells. These genes are related to the organization of the actin cytoskeleton network. Moreover, the majority of these genes are preferentially expressed in the hematopoietic lineage and at least three of them, Was (Wiskott Aldrich syndrome), Btk (Bruton's tyrosine kinase) and Rac2, when mutated in humans, give rise to severe hematopoietic deficiencies. Among the group of genes that were up-regulated in MEL-R cells, $16 \%$ of genes code for histone proteins, both canonical and variants. A potential implication of these results on the blockade of differentiation in resistant cells is discussed. 
1 Title: "Differential Gene Expression Analysis by RNA-seq Reveals the Importance of Actin

2

3

4

5

6

7 10 Madrid, Spain

11

12

13

14

15

16

17

18

19

Cytoskeletal Proteins in Erythroleukemia Cells"

\author{
8 Address: ${ }^{1}$ Department of Cellular and Molecular Biology, ${ }^{2}$ Bioinformatics and Biostatistics \\ 9 Service, Centro de Investigaciones Biológicas, Spanish National Research Council (CSIC), \\ Authors: Vanessa Fernández-Calleja ${ }^{1}$, Pablo Hernández ${ }^{1}$, Jorge B. Schvartzman ${ }^{1}$, Mario García \\ de Lacoba ${ }^{2}$ and Dora B. Krimer ${ }^{1 \#}$
}

Running Title: Differential Expression in Leukemia Cells

3

14

\#Corresponding author: Dora B. Krimer

Phone: (+34) 918373112 ext. 4238

Fax: (+34) 915360432

E-mail: dbkrimer@cib.csic.es 
21 Abstract

22

23 Development of drug resistance limits the effectiveness of anticancer treatments. Understanding 24 the molecular mechanisms triggering this event in tumor cells may lead to improved therapeutic 25 strategies. Here we used RNA-seq to compare the transcriptomes of a murine erythroleukemia 26 cell line (MEL) and a derived cell line with induced resistance to differentiation (MEL-R). RNA27 seq analysis identified a total of 596 genes (Benjamini-Hochberg adjusted p-value $<0.05)$ that 28 were differentially expressed by more than two-fold, of which 81.5\% (486/596) of genes were 29 up-regulated in MEL cells and 110 up-regulated in MEL-R cells. These observations revealed 30 that for some genes the relative expression of mRNA amount in the MEL cell line has decreased 31 as the cells acquired the resistant phenotype. Clustering analysis of a group of genes showing the 32 highest differential expression allowed identification of a sub-group among genes up-regulated 33 in MEL cells. These genes are related to the organization of the actin cytoskeleton network.

34 Moreover, the majority of these genes are preferentially expressed in the hematopoietic lineage 35 and at least three of them, Was (Wiskott Aldrich syndrome), Btk (Bruton's tyrosine kinase) and 36 Rac2, when mutated in humans, give rise to severe hematopoietic deficiencies. Among the group 37 of genes that were up-regulated in MEL-R cells, 16\% of genes code for histone proteins, both 38 canonical and variants. A potential implication of these results on the blockade of differentiation 39 in resistant cells is discussed. 
41 Introduction

42

43 Cancer cells are distinguished from their normal counterparts by several hallmarks, including 44 uncontrolled growth, lack of response to apoptotic signals and blockade of differentiation 45 (Hanahan \& Weinberg 2000; Hanahan \& Weinberg 2011). These characteristics serve as a 46 framework for testing different protocols aimed at eliminating tumor cells by aggressive 47 chemotherapy or radiotherapy. Alternatively, cancer cells may be forced to resume the process of 48 maturation by differentiation agents, which generally have less toxicity than conventional cancer 49 treatments. An example of a successful clinical application of differentiation therapy is all-transretinoic acid (ATRA) for treatment of acute promyelocytic leukemia, which induces terminal

51 differentiation of promyelocytic leukemic cells (Nowak et al. 2009). Other differentiation-

52 inducing agents, such as histone-deacetylase (HDAC) inhibitors (Lane \& Chabner 2009), 53 cytidine analogs (e.g. 5'-aza-2'-deoxycytidine) (Fenaux et al. 2010), and tyrosine kinase 54 inhibitors (e.g., imatinib) (Haouala et al. 2011) have been less successful in the treatment of 55 leukemias and solid tumor cancers. An obstacle to all cancer therapies is the acquisition of drug 56 resistance that develops in response to repeated therapies, which eventually leads to relapse in most patients (Rebucci \& Michiels 2013).

In vitro differentiation models have proved to be extremely useful to study the molecular events associated with the blockade of cell differentiation exhibited by some tumor cells and the requirements for re-entry into the cell differentiation program. The mouse erythroleukemia (MEL) model developed by Friend et al. (1971) is an outstanding example that remains as a solid platform to evaluate tumor cell reprogramming after more than 40 years since its 64 description.

66 Friend erythroblasts are derived from mice infected with the Friend complex virus. Insertion of 67 the Friend spleen focus-forming virus (SFFV) genome occurs several kilobases upstream of the Sfpil/PU.1 locus initiation start site (Fernández-Nestosa et al. 2013). This causes the constitutive activation of Sfpi/PU.1 resulting in the blocking of erythroid differentiation and the development of erythroleukemia (reviewed in Ruscetti 1999). MEL cells can be induced to reinitiate the 
72 (HMBA) (Fernández-Nestosa et al. 2008). We have previously reported the establishment of an 73 HMBA-resistant cell line (MEL-R) before. These cells were obtained after months of MEL cell 74 culture in the presence of a differentiation inducer. The resulting cell line retained most of the 75 native MEL cell characteristics. Unexpectedly, we found that Sfpil/PU.1 remains silent even 76 though MEL-R cells do not differentiate, and this silencing persists in the presence of chemical 77 inducers other than HMBA. Nevertheless, the SFFV integration site maps exactly to the same 78 location both in MEL and MEL-R cell lines (2,976 bp downstream of the URE distal element). 79 We also showed that inactivation of Sfpil/PU.1 in the resistant MEL-R cell line was mediated by 80 DNA methylation at the promoter near to CpG islands (Fernández-Nestosa et al. 2013). For all

81 these reasons, we believe MEL-R cells might constitute a useful model to study mechanisms that 82 trigger inducer-resistant cell differentiation. Here we compared the differential expression 83 profiles of MEL and MEL-R cells using RNA-seq to identify sequences potentially involved in 84 the control of HMBA resistance. Our results revealed that a higher proportion of differentially85 expressed genes are up-regulated in MEL cells than in MEL-R cells. Interestingly, a group of 86 highly up-regulated sequences in MEL cells corresponded to genes encoding actin cytoskeleton 87 proteins. A proportion of genes up-regulated in MEL-R cells belonged to histone coding genes. 88 Canonical histone proteins $\mathrm{H} 1, \mathrm{H} 2 \mathrm{~A}, \mathrm{H} 2 \mathrm{~B}, \mathrm{H} 3$ and H4, are replication-dependent and their 89 expression is coordinated with DNA replication, occurring primarily during the S phase of the 90 cell cycle (Rattray \& Muller 2012). There are nonallelic variants mainly of the H1, H2A, H2B and $\mathrm{H} 3$ histones that are not restricted in their expression to the S phase and have different physiological roles. Both groups, however, are essential elements of the nucleosome architecture

94 histone gene expression to the differentiation block is also discussed.

95

96

97 Materials and Methods

98

99 Cell cultures and treatment

100 MEL-DS19 cell line (hereafter called MEL) was obtained from Arthur Skoultchi (Albert Einstein 101 College of Medicine, New York, USA). MEL-resistant cell line (hereafter called MEL-R) 102 derived from MEL-DS19 was previously established in our lab by growing MEL cells 
103 continuously in the presence of 5mM HMBA (Fernández-Nestosa et al. 2008). 3T3-Swiss albino

104 fibroblasts cells were obtained from the Animal Cell Culture Facility from the Centro de

105 Investigaciones Biológicas, CSIC. Cells were cultured in Dulbecco's modified Eagle's medium

106 containing 10\% fetal bovine serum, 100 units $/ \mathrm{ml}$ penicillin and $100 \mu \mathrm{g} / \mathrm{ml}$ streptomycin (Gibco).

107 Cell differentiation was induced by exposing logarithmically growing cell cultures to $5 \mathrm{mM}$

108 HMBA. MEL-R cells were routinely cultured in the presence of $5 \mathrm{mM}$ HMBA. Hemoglobinized

109 cells were quantified by determining the proportion of benzidine-staining positive cells $\left(\mathrm{B}^{+}\right)$in

110 the culture.

111

112 RNA isolation and RNA-seq analysis

113 Total RNA was isolated from $1 \times 10^{7}$ cells using the RNeasy kit (Qiagen). DNase I was used to

114 degrade any possible DNA contamination. $1 \mu \mathrm{g}$ of total RNA was used to prepare standard

115 RNA-seq libraries (TruSeq RNA Sample Preparation Kit, Illumina) based on polyA ${ }^{+}$isolation.

116 RNA concentration ranged from 326 to $394 \mathrm{ng} / \mu \mathrm{l}$, and samples showed optimal integrity with

117 RIN values of 9.80. The libraries had an average length of 337-367 nt and were quantified by

118 quantitative PCR (Kapa Biosystems) using a previously quantified library as standard. Samples

119 were loaded onto a lane of a flowcell using the Cluster Station apparatus (Illumina) and

120 sequenced on the Illumina GAIIx platform (Parque Científico de Madrid, Spain) under a single

121 read $(1 \times 75)$ protocol. There were approximately 25 million and 17 million reads (75-nt length)

122 for MEL and MEL-R libraries, respectively, which were used for further bioinformatics analysis.

123 The median quality score was $>30$ across all sites of the reads

124 (http://hannonlab.cshl.edu/fastx_toolkit/index.html). The sequencing reads were mapped to the

125 mouse reference genome (Mus_musculus_NCBI_build37.67.cdna, 30-04-2012) with TopHat

126 v2.0.1. TopHat's mapped reads were processed using the program Cuffdiff, a part of the

127 Cufflinks software suite v2.0.0 (Trapnell et al. 2012) and measured as fragments per kb of exon

128 per million fragments mapped (FPKM) (Trapnell et al. 2012). The workflow outlining the

129 analysis of RNA sequencing data is shown in Fig S1. Samples (unreplicated MEL and MEL-R)

130 were further analyzed using the DESeq package for R Statistical Analysis (Anders \& Huber

131 2010). We used DESeq as a complementary differential gene expression analysis to compare the

132 results with those obtained by Cuffdiff (Fig S2). DESeq was employed as an additional DEG

133 calling method since it performs a different expression test (Fishers' exact test) than Cuffdiff (t- 
134 test). A list of differentially expressed genes detected with both methodologies is included in

135 Supplementary Material (Cuffdiff/DESeq analysis).

136

137 Quantitative real-time PCR validation

138 Quantitative real-time-PCR (qRT-PCR) was used to validate the relative expression of genes 139 selected from the RNA-seq analysis. Total RNA was extracted from $1 \times 10^{7}$ MEL and MEL-R 140 cells as described above. In total, $2 \mu \mathrm{g}$ of isolated RNA were transcribed to cDNA using random 141 hexamers and $200 \mathrm{U}$ of SuperScriptII Reverse Transcriptase (Invitrogen). Reactions were 142 performed in triplicate using the SYBR Green Supermix (Bio-Rad) on an iQ5 System (Bio-

$143 \mathrm{Rad}$,). The conditions for the amplification were as follows: pre-denaturing step of $95^{\circ} \mathrm{C}$ for 3

$144 \mathrm{~min}$ followed by 40 cycles of $95^{\circ} \mathrm{C}$ for $30 \mathrm{sec}$ and $60^{\circ} \mathrm{C}$ for $30 \mathrm{sec}$, and a final ramp step of $1451^{\circ} \mathrm{C} / 10 \mathrm{sec}$ from $60^{\circ} \mathrm{C}$ to $94^{\circ} \mathrm{C}$. The primer sequences were designed with Primer 3 software 146 (http://bioinfo.ut.ee/primer3-0.4.0/) (Untergasser et al. 2012) and are listed in Table S1 (for actin 147 cytoskeleton genes), Table S2 (for histone genes) and Table S3 (for methylases and 148 demethylases). Relative gene expression was analyzed by the $2^{-\Delta \Delta \mathrm{Ct}}$ method as described in 149 Schmittgen \& Livak (2008).

150

151 Antibodies and Western blotting

152 Control 3T3 fibroblast cells, MEL and MEL-R cells $\left(2.5 \times 10^{6}\right)$ were harvested, washed with PBS 153 and lysed with NP-40 buffer (20 mM Tris- $\mathrm{HCl}$ pH 7.5, 10\% glycerol, $137 \mathrm{mM} \mathrm{NaCl}, 1 \%$ NP$15440,1 \mathrm{mM}$ sodium orthovanadate, $10 \mathrm{mM}$ sodium fluoride, $2 \mathrm{mM}$ EDTA) containing protease 155 inhibitors (all from Sigma). Protein lysates (10-30 $\mu \mathrm{g}$ ) were separated by $12 \%$ SDS-

156 polyacrylamide gel electrophoresis and transferred to PVDF membranes (Bio-Rad). The 157 membranes were incubated with a mouse monoclonal anti- $\beta$-actin antibody (1:10000, Sigma) 158 and a rabbit polyclonal anti- $\alpha$-tubulin antibody (1:1000, ABclonal) followed by five washing 159 steps with T-TBS (20 mM Tris- $\mathrm{HCl}, 150 \mathrm{mM} \mathrm{NaCl}, 0.1 \%$ Tween 20). Primary antibodies were 160 detected by incubating with HRP-conjugated anti-mouse (1:3000, Santa Cruz) or anti-rabbit IgG

161 (1:1000, DAKO) followed by five cycles of T-TBS washes. HP1 $\alpha$ (1:1000, Millipore) and 162 Sam68 (1:1000, Santa Cruz) antibodies were used for Fig S3.

163

164 Bisulfite sequencing 
165 The methylation analysis of Btk, Plek and Was promoter regions in MEL, MEL-R and

166 differentiated MEL cells was performed using sodium bisulfite conversion. Genomic DNA from

$1678 \times 10^{4}$ cells was bisulfite-modified using the EZ DNA Methylation-Direct Kit (Zymo Research).

168 Four microlitres of treated DNA was amplified by PCR using primers specific to the bisulfite-

169 converted DNA for each promoter region with ZymoTaq DNA Polymerase (Zymo Research).

170 The conditions for the PCR were as follows: pre-denaturing step of $95^{\circ} \mathrm{C}$ for $10 \mathrm{~min}$, followed by

17140 cycles of $95^{\circ} \mathrm{C}$ for $30 \mathrm{sec}, 55-60^{\circ} \mathrm{C}$ for $40 \mathrm{sec}$ and $72^{\circ} \mathrm{C}$ for $40 \mathrm{sec}$, with a final extension at

$17272^{\circ} \mathrm{C}$ for $7 \mathrm{~min}$. The primer sequences were designed using MethPrimer software

173 (http://www.urogene.org/cgi-bin/methprimer/methprimer.cgi) (Li \& Dahiya 2002). The primers

174 are listed in Table S4. PCR products were resolved in 1\% agarose gels followed by sequencing

175 for methylation analysis, which was performed by Secugen SL (CIB, Madrid).

176

177 Cell cycle analysis

178 Cells $\left(2 \times 10^{5}-1 \times 10^{6}\right)$ were harvested and fixed in $70 \%$ ethanol at $4^{\circ} \mathrm{C}$ for $30 \mathrm{~min}$. Fixed cells

179 were washed twice in PBS and stained with propidium iodide/RNAse solution (Immunostep) for

$18015 \mathrm{~min}$ at room temperature ( 22 degrees Celsius). Cell cycle analysis was performed on a

181 Coulter EPICS XL (Beckman) flow cytometer and cell cycle profiles were plotted using FlowJo

182 software (Tree Star, Inc.) All samples were analyzed at least in triplicates for each experiment.

183

184 Immunocytochemistry and confocal microscopy

185 Cells were plated on poly-L-lysine coated slides and incubated at $37^{\circ} \mathrm{C}$ for $30 \mathrm{~min}$. Cells were

186 fixed with 4\% paraformaldehyde for $30 \mathrm{~min}$, permeabilized with $0.1 \%$ Triton-X 100 in PBS for

18730 min and blocked with 1\% bovine serum albumin in PBS/0.1\% Triton-X 100 for $1 \mathrm{~h}$, all at RT.

188 Cells were stained with anti- $\beta$-actin (Sigma) or anti-HP1 $\alpha$ (Millipore) antibodies, for $1 \mathrm{~h}$ at RT

189 followed by washing twice with PBS. The primary antibody was detected with an Alexa Fluor

190568 secondary antibody (Molecular Probes) and $1 \mu \mathrm{g} / \mathrm{ml}$ DAPI to stain nuclei, for $1 \mathrm{~h}$ at RT

191 followed by two washes with PBS. Finally, cells were mounted on a cover slip with Prolong

192 Diamond Antifade Mountant reagent (Invitrogen). Fluorescence images were acquired on a

193 Leica TCS SP2 confocal microscope using a 100× objective with zoom.

194

195

Data access 
196 The raw data files generated by RNA-seq have been deposited in the Gene Expression Omnibus

197 (GEO) database, available at https://www.ncbi.nlm.nih.gov/geo/query/acc.cgi?acc=GSE83567.

198

199

200 Results

201

202

Differential gene expression between MEL and MEL-R

203 A total number of 25791 genes were identified and deposited at the GEO database (GSE83567).

204596 genes (Benjamini-Hochberg adjusted p-value $<0.05$ ) were differentially expressed by more 205 than two-fold between MEL and MEL-R cells, of which 486 genes were up-regulated in MEL 206 cells and 110 were up-regulated in MEL-R cells. We focused our attention on sequences that 207 were highly differentially expressed in MEL relative to MEL-R cells. Fig 1A illustrates the heat 208 map that includes all the genes, clustered based on Ward's analysis of minimum variance 209 criterion (Ward 1963), with fold change of 2 or more using Cuffdiff. An expanded heat map of 210 genes showing highest fold-change values is shown in Fig 1B. Sfpi1/PU.1 was one of the 211 selected genes that, as we demonstrated previously (Fernández-Nestosa et al. 2008), is not 212 expressed in the resistant cell line and served in this case as a positive control for the RNA-seq 213 efficiency. We observed that the majority of the differentially expressed genes are up-regulated 214 in MEL compare to MEL-R cells (Fig 1A and Fig S2).

216 Searching for common features among the cohort of highly expressed genes in MEL cells, we 217 found that several of these genes were implicated in the regulation of the actin cytoskeleton 218 organization. Table 1 lists the groups of these genes with the highest expression difference 219 between MEL and MEL-R cell lines. In addition to their relationship with the actin pathway, 220 eight of these genes (Btk, Dock2, Itgb2, Nckap1l, Plek, Rac2, Was and Wdfy4) were 221 preferentially expressed in hematopoietic cells (www.proteinatlas.org) and at least three of them, 222 Was (Wiskott Aldrich syndrome), Btk (Bruton's tyrosine kinase) and Rac2, when mutated in 223 humans, give rise to severe deficiencies (Ambruso et al. 2000; Bosticardo et al. 2009; Conley et 224 al. 2009). The majority of these genes were mostly linked to the lymphoid or myeloid lineages, 225 and several were reported in an erythroid context (Schmidt et al. 2004). 
227 Among the 110 selected genes whose expression was higher in MEL-R cells than in the

228 progenitor cell line, 16\% encode histone proteins, mostly canonical but also variant histone

229 types. An expanded heat map illustrating the differential gene expression of histones in MEL-R

230 vs MEL cell lines is shown in Fig 1C. The RNA-seq data revealed differences in the expression

231 of histones that belong to canonical H1, H2A, H2B and H3 groups, and to the variant histones

$232 \mathrm{H} 1 \mathrm{f0}, \mathrm{H} 2 \mathrm{afx}$ and H3f3b. To understand the significance of the unexpected up-regulation of

233 histone gene expression in MEL-R cells, we compared their DNA content with that of

234 undifferentiated and HMBA-differentiated MEL cells by flow cytometry (Fig 2). We found that

235 the pattern of the major cell cycle phases, G1 vs S vs G2/M, was similar between MEL-R cells

236 and undifferentiated MEL progenitors (MEL-0h). By contrast, differentiated MEL cells (MEL-

237 96h) accumulated at G1, a phenomenon that has been previously observed during MEL cell

238 differentiation (Kiyokawa et al. 1993; Vanegas et al. 2003; Fernández-Nestosa et al. 2008).

239 Nevertheless, we observed that in terms of DNA content, MEL-R cells acquired a tetraploid

240 phenotype as revealed by the shift in DNA content to the right (Fig 2, panel C).

242 Validation of differentially expressed genes by $q R T-P C R$

243 To validate the results obtained by RNA-seq, we measured the expression fold changes of seven 244 selected genes by qRT-PCR. Those genes (marked with a red asterisk in Table 1), were selected

245 as they showed highest differential expression values, were related to the actin cytoskeletal

246 network and had hematopoietic specificity. RNA from MEL cells treated with 5 mM HMBA

247 were included to allow comparison between the undifferentiated and differentiated MEL cells

248 against the resistant MEL-R line. The expression patterns observed in all cases were consistent

249 with the RNA-seq results (Fig 3), confirming the near absence of expression of those genes in

250 MEL-R cells. Significant differences were detected, however, when MEL-R cells were compared

251 with MEL cells induced to differentiate with HMBA. Some of the genes such as Was, Rac2,

252 Dock 2 or Btk shared a similar expression profile to that obtained in the resistant cell line,

253 showing a tendency toward minimal expression, whereas the expression levels of Plek,

254 Arhgef10l or Nckap1l exhibited either no change or a higher expression than that observed in

255 differentiated cells.

256 
257 Validation by qRT-PCR was also performed for histone genes and as before, we included a 258 comparison with HMBA-differentiated MEL cells. The results of the qRT-PCR analysis were in 259 agreement with those of the RNA-seq; in all cases, histone gene expression was higher in MEL$260 \mathrm{R}$ cells than in MEL cells (Fig 4A). The difference in the level of expression varied from more 261 than ten-fold (Hist1h2bk) to two-fold (Hist1h2bn), except for Hist1h2bj with values close to 1.

262 The same pattern was observed between the differentiated (MEL-96h) and undifferentiated 263 samples (Fig 4B). These results ruled out the hypothesis that MEL-R tetraploidy was responsible 264 for histone gene over-expression.

265

266

267

Methylation status of CpG island promoters of Was, Btk and Plek

268

We have previously demonstrated that Sfpil/PU.1 silencing in MEL-R cells is caused by

269 methylation of nearby $\mathrm{CpG}$ islands at its promoter (Fernández-Nestosa et al. 2013). Moreover, reactivation of silenced Sfpil/PU.1 occurs after treatment with 5-aza-2'-deoxycytidine, a potent inhibitor of DNA methylation. To investigate whether DNA methylation is responsible for the down-regulation in gene expression, we examined the methylation status of Btk, Was and Plek promoters in undifferentiated and differentiated MEL cells and in MEL-R cells by bisulfite sequencing. We mapped seven $\mathrm{CpG}$ islands upstream of the transcriptional start site of Btk and Was (Fig 5A and B) and five in the case of Plek (Fig 5C). Bisulphite sequencing revealed that all the CpG sites were hypomethylated in undifferentiated $(0 \mathrm{~h})$ and differentiated $(96 \mathrm{~h}) \mathrm{MEL}$ cells, whereas the promoters remained hypermethylated at all $\mathrm{CpG}$ sites in the resistant cell line. Sites 3, 4 and 5 at the Btk promoter were within a highly cytosine-rich region that were converted to thymine after bisulfite treatment, becoming difficult to resolve. We concluded from these experiments that Btk, Was and Plek expression was silenced by promoter methylation in MEL-R cell lines.

To confirm these results, we examined the expression pattern of the enzymes that catalyze DNA methylation (Dnmt1, Dnmt3a and Dnmt3b) and those that are involved in demethylation processes (Tet1, Tet2 and Tet3). Quantitative RT-PCR analysis revealed that the level of expression of Dnmt1, the maintenance methylase enzyme, was higher in MEL-R cells than in undifferentiated or differentiated MEL cells, whereas the smallest changes were detected for the de novo methylases Dnmt3a and Dnmt3b between the different cell populations (Fig 6A, B and 
288 C). By contrast, expression of Tet3, but not Tet1 and Tet2 (enzymes involved in methyl group 289 removal), was markedly reduced in MEL-R cells (Fig 6D, E and F). These results showed that 290 the increase in DNA methylation by Dnmt1 in MEL-R cells overlaps with a decrease in 291 demethylation by Tet3, which presumably results in the silencing of Btk, Was and Plek 292 promoters.

293

294

Actin cytoskeleton is poorly organized in resistant erythroleukemia cells

295 The actin cytoskeleton is composed of an extensive variety of actin regulators and nucleators that 296 interact through a complicated protein network (Moulding et al. 2013; Bezanilla et al. 2015). Our analysis indicated that the expression of a group of genes related to actin cytoskeleton organization was depressed in the resistant erythroleukemia cell line. To examine whether actin was affected by the silencing of genes related to actin polymerization and/or regulation, we evaluated its protein expression by Western blotting and found that its levels were similar between MEL and MEL-R cells (Fig 7).

302

While these results demonstrate that the total amount of actin is equivalent for both cell lines, it 304 does not reveal details of the actin organization. We therefore used fluorescence

305

306

307

308

309

310

311

312

313

314

315

316 318 317 therapies, and such an occurrence remains a great concern in cancer treatment (Raguz \& Yague immunocytochemistry and confocal microscopy with anti-actin antibody to localize the protein in fixed MEL and MEL-R cells. In both populations, a rim of actin fluorescence was observed surrounding the nuclei (Fig 8). However, MEL-R cells showed a significant reduction of signal intensity. These results were consistent with the RNA-seq analysis, where a marked reduction in the expression of actin-regulators genes was detected in MEL-R cells, suggesting that actin cytoskeleton organization is perturbed in the resistant erythroleukemia cell line.

13 Discussion

Actin-regulatory proteins are preferentially expressed in murine erythroleukemia cells.

16 Cancer cells can acquire resistance to most traditional chemotherapy regimes and also targeted 2008; Rebucci \& Michiels 2013). Research on molecular and cellular mechanisms that confer 
319 resistance to tumor cells is therefore a major focus of basic and clinical investigation. Along this

320 line, cell culture models have been crucial to advancing the understanding of cancer cell

321 resistance. We took advantage of an HMBA-resistant cell line derived from murine

322 erythroleukemia cells, previously established in our lab (Fernández-Nestosa et al. 2008;

323 Fernández-Nestosa et al. 2013), to study the molecular events that contribute to the resistant

324 phenotype. Both MEL and MEL-R cell lines are blocked at the proerythroblast stage of

325 differentiation but unlike the progenitor cell line, MEL-R cells do not react to HMBA or other

326 chemical inducers (e.g., DMSO, hemin and butyrate) and remain resistant against cell

327 differentiation. In the present study, we used RNA-seq technology to identify genes potentially

328 involved in the resistance mechanism. Our analysis identified 596 genes that were differentially

329 expressed between progenitor and resistant cells, with the majority corresponding to genes up-

330 regulated in MEL cells while only 110 were up-regulated in MEL-R cells.

331

332 Among these identified genes, some of them were prominent by their high expression in MEL

333 compared to MEL-R and for sharing two important features: belonging to the actin regulatory

334 network and being preferentially expressed in the hematopoietic lineage. Also, at least three

335 genes, Was, Btk and Rac2, when mutated are linked to severe human hematological pathologies

336 (Ambruso et al. 2000; Bosticardo et al. 2009; Conley et al. 2009). Additionally, a recent study

337 showed that biallelic mutations in the Dock2 gene result in severe immunodeficiency that leads

338 to defects in actin polymerization (Dobbs et al. 2015). We hypothesized that proteins of the actin

339 network such as Btk, Was and Plek among others described in Table 1, are essential for such

340 organization although it is unclear whether the absence of expression is a cause or consequence

341 of the defect.

342

343 Transcriptional down-regulation of Was, Btk and Plek correlate with DNA promoter methylation

344 The network of actin filaments provides mechanical support to the cell cytoskeleton, but it is

345 increasingly acknowledged that it also contributes to other critical cellular processes. Emerging

346 evidence points to a role for the actin cytoskeleton in controlling and regulating receptor

347 signaling (Mattila et al. 2016). We show here a dramatic down-regulation of some of these

348 network components in MEL-R cells, which show a relationship with the methylation status at

349 nearby $\mathrm{CpG}$ islands in the promoters of Was, Btk and Plek. Over-expression of the 
350 methyltransferase Dnmt1, a maintenance methylase that acts on hemimethylated DNA, and the

351 repression of the demethylase Tet3, supported these findings. These observations led us to

352 speculate that silencing of most of the cytoskeleton-associated proteins is linked to a

353 hypermethylation status. Interestingly, whereas no significant changes in total actin protein

354 levels were observed between MEL and MEL-R cells, weaker signals were detected in MEL-R

355 cells by immunocytochemistry. This observation might indicate poor actin organization.

356 Regulation of actin polymerization in eukaryotes requires a large number of accessory proteins.

357 These proteins facilitate polymerization or disassembly of monomeric globular actin (G-actin)

358 into filamentous actin (F-actin) and vice versa. Many of these proteins interact with each other.

359 For example, Btk interacts with Was and activates the protein by inducing its phosphorylation in

360 B cells (Sharma et al. 2009). Btk also promotes a Rac2 response, leading to F-actin

361 rearrangements in mast cells (Kuehn et al. 2010). Dock2 is essential for lymphocyte migration

362 and mediates cytoskeletal reorganization through Rac2 activation (Fukui et al. 2001). The

363 transcription factor PU.1, responsible for the differentiation block in MEL cells but silenced in

364 MEL-R cells, is a major regulator of Btk expression both in myeloid and lymphoid cells

365 (Himmelmann et al. 1996; Christie et al. 2015). In summary, the actin cytoskeleton network is

366 orchestrated by multiple associated proteins with possible overlapping roles, which contribute to

367 different cell functions through complex associations. As we showed here, silencing of some of

368 these proteins has deleterious effects on actin organization and we speculate that this might be a

369 cause for the blockade of differentiation in resistant cells.

370

371 Increased expression of histone-coding genes characterizes MEL-R cells transcriptome

372 As stated earlier, only 110 from 596 differentially-expressed genes were up-regulated in MEL-R

373 cells. This indicates a tendency towards a general decline of gene expression in resistant cells, a

374 situation comparable with what occurs during cell differentiation. Silenced compartments

375 composed mainly of heterochromatin are considered hallmarks of the differentiated cells, a

376 condition that progresses all through terminal differentiation (reviewed in Politz et al. 2013). A

377 gradual increase in heterochromatinization has been described in differentiating leukemia cells,

378 as measured by the amount of the heterochromatin-associated HP1 $\alpha$, which increases

379 continuously during MEL differentiation (Estefania et al. 2012). Heterochromatinization is

380 enhanced in MEL-R cells relative to undifferentiated MEL cells, but is nevertheless lower than 
381 in HMBA-differentiated cells (Fig S3). The progressive gene silencing observed in MEL-R cells

382 is one additional element that suggests that these cells are at a midway point between the

383 undifferentiated and differentiated phenotypes due to a block somewhere in the process.

384 Concomitant with this gene silencing, histone genes emerge as the major group up-regulated in

385 the resistant phenotype. Initially, we associated the histone gene expression pattern with the 386 tetraploid status of the MEL-R cell lines. Polyploidy has been reported in tumor cells as a result 387 of stress-induced endoreplication (Storchova \& Pellman 2004; Lee et al. 2009). Chronic HMBA 388 treatment might represent a hard-hitting stress that MEL-R cells overcome via a survival 389 phenotype, i.e. tetraploidization, increased cell size and impaired cell differentiation. Coward \& 390 Harding (2014) in a comprehensive perspective support the hypothesis that tetraploidy provides 391 numerous advantages during tumor initiation. Moreover, they present data supporting that 392 polyploidy facilitates the acquisition of therapy-resistance in multiple cancers. MEL-R 393 tetraploidy may possibly involve chromatin rearrangements and consequently histone gene 394 expression changes. Nevertheless, the same fluctuations in histone gene expression were 395 observed in differentiated cells, indicating that differentiated and resistant cells share a common 396 mechanism not related to tetraploidy. In vivo, the quantity of reticulocytes, at a stage comparable 397 to the last stages of HMBA-induced differentiation, increases several fold in a very short time (Ji 398 et al. 2008). It is speculated that a large number of histones needs to be generated. When 399 reticulocytes mature, before enucleation, major histones are released into the cytoplasm thru an 400 unexpected nuclear opening that arises during terminal erythropoiesis. This migration is crucial 401 for chromatin condensation and terminal differentiation (Zhao et al. 2016). We speculate that as 402 an increase in histones occur both in HMBA-differentiated MEL and in MEL-R cells, a failure in 403 chromatin condensation, either by an impairment in histone release or by a yet unknown 404 mechanism, might interfere with terminal cell differentiation in resistant cells.

405

406

407 Conclusions

408

409

410

411
A genome-wide RNA-seq analysis revealed that a subset of genes had significantly lower levels of expression in MEL-R cells compared to MEL cells. Among the differentially expressed genes, a group up-regulated in the MEL cell line correspond to proteins related to the actin cytoskeleton 
412 organization. We showed here that the expression of these genes, i.e. Was (Wiskott-Aldrich

413 syndrome), Btk (Bruton's tyrosine kinase) or Plek (Pleckstrin), among others, is very low in the

414 resistant phenotype MEL-R. Immunocytochemistry and confocal microscopy analysis

415 demonstrated an abnormal actin pattern in MEL-R cells, but the total amount of actin protein is

416 equivalent for both, MEL-R and MEL. These results suggest that silencing of actin-related

417 proteins influence the organization of the cytoskeleton. Among the group of genes that were up-

418 regulated in MEL-R cells, histone proteins, both canonical and variants, were relevant.

419

420

421 Acknowledgements

422

423 We acknowledge María-José Fernández Nestosa for her suggestions and critical reading of the

424 manuscript, Alicia Bernabé for technical help and Eduardo Larriba for helping with the

425 bioinformatics programs. We are grateful to the team from the Bioinformatics and Biostatistics

426 Facility at the CIB for their efficient and dedicated technical support for the Next Generation

427 Sequencing data analysis. We acknowledge Dr Tsung Fei Khang and two other anonymous

428 reviewers as well as Dr Elena Papaleo acting as Academic Editor for their helpful comments that

429 produce the final version of the manuscript.

430

431

432 References

433

434

435

436

437

438

439

440

441

442

443

444

Ambruso DR, Knall C, Abell AN, Panepinto J, Kurkchubasche A, Thurman G, Gonzalez-Aller C, Hiester A, deBoer M, Harbeck RJ, Oyer R, Johnson GL, and Roos D. 2000. Human neutrophil immunodeficiency syndrome is associated with an inhibitory Rac2 mutation. Proc Natl Acad Sci U S A 97:4654-4659.

Anders S, and Huber W. 2010. Differential expression analysis for sequence count data. Genome Biol 11:R106. 10.1186/gb-2010-11-10-r106

Bezanilla M, Gladfelter AS, Kovar DR, and Lee WL. 2015. Cytoskeletal dynamics: a view from the membrane. J Cell Biol 209:329-337.

Bosticardo M, Marangoni F, Aiuti A, Villa A, and Grazia Roncarolo M. 2009. Recent advances in understanding the pathophysiology of Wiskott-Aldrich syndrome. Blood 113:6288-6295. 
446

447

448

449

450

451

452

453

454

455

456

457

458

459

460

461

462

463

464

465

466

467

468

469

470

471

472

473

474

475

476

477

478

479

480

481

482

483

484

485

486

487

488

489
445 Conley ME, Dobbs AK, Farmer DM, Kilic S, Paris K, Grigoriadou S, Coustan-Smith E, Howard V, and Campana D. 2009. Primary B cell immunodeficiencies: comparisons and contrasts. Annu Rev Immunol 27:199-227.

Coward J, and Harding A. 2014. Size Does Matter: Why Polyploid Tumor Cells are Critical Drug Targets in the War on Cancer. Front Oncol 4:123.

Christie DA, Xu LS, Turkistany SA, Solomon LA, Li SK, Yim E, Welch I, Bell GI, Hess DA, and DeKoter RP. 2015. PU.1 opposes IL-7-dependent proliferation of developing B cells with involvement of the direct target gene bruton tyrosine kinase.J Immunol 194:595-605.

Dobbs K, Domínguez Conde C, Zhang SY, Parolini S, Audry M, Chou J, Haapaniemi E, Keles S, Bilic I, Okada S, Massaad MJ, Rounioja S, Alwahadneh AM, Serwas NK, Capuder K, Ciftci E, Felgentreff K, Ohsumi TK, Pedergnana V, Boisson B, Haskologlu S, Ensari A, Schuster M, Moretta A, Itan Y, Patrizi O, Rozenberg F, Lebon P, Saarela J, Knip M, Petrovski S, Goldstein DB, Parrott RE, Savas B, Schambach A, Tabellini G, Bock C, Chatila TA, Comeau AM, Geha RS, Abel L, Buckley RH, Ikinciogullari A, Al-Herz W, Helminen M, Dogu F, Casanova JL, Boztug K, and Notarangelo LD. 2015. Inherited DOCK2 Deficiency in Patients with Early-Onset Invasive Infections. N Engl J Med 372:2409-2422.

Estefania MM, Ganier O, Hernández P, Schvartzman JB, Mechali M, and Krimer DB. 2012. DNA replication fading as proliferating cells advance in their commitment to terminal differentiation. Sci Rep 2:279.

Fenaux P, Mufti GJ, Hellstrom-Lindberg E, Santini V, Gattermann N, Germing U, Sanz G, List AF, Gore S, Seymour JF, Dombret H, Backstrom J, Zimmerman L, McKenzie D, Beach CL, and Silverman LR. 2010. Azacitidine prolongs overall survival compared with conventional care regimens in elderly patients with low bone marrow blast count acute myeloid leukemia. J Clin Oncol 28:562-569.

Fernández-Nestosa MJ, Hernández P, Schvartzman JB, and Krimer DB. 2008. PU.1 is dispensable to block erythroid differentiation in Friend erythroleukemia cells. Leuk Res 32:121-130.

Fernández-Nestosa MJ, Monturus E, Sánchez Z, Torres FS, Fernández AF, Fraga MF, Hernández P, Schvartzman JB, and Krimer DB. 2013. DNA methylation-mediated silencing of PU.1 in leukemia cells resistant to cell differentiation. Springerplus 2:392.

Friend C, Scher W, Holland JG, and Sato T. 1971. Hemoglobin synthesis in murine virusinduced leukemic cells in vitro: stimulation of erythroid differentiation by dimethyl sulfoxide. Proc Natl Acad Sci U S A 68:378-382.

Fukui Y, Hashimoto O, Sanui T, Oono T, Koga H, Abe M, Inayoshi A, Noda M, Oike M, Shirai T, and Sasazuki T. 2001. Haematopoietic cell-specific CDM family protein DOCK2 is essential for lymphocyte migration. Nature 412:826-831.

Hanahan D, and Weinberg RA. 2000. The hallmarks of cancer. Cell 100:57-70.

Hanahan D, and Weinberg RA. 2011. Hallmarks of cancer: the next generation. Cell 144:646-674.

Haouala A, Widmer N, Duchosal MA, Montemurro M, Buclin T, and Decosterd LA. 2011. Drug interactions with the tyrosine kinase inhibitors imatinib, dasatinib, and nilotinib. Blood 117:e75-87. 
490

491

492

493

494

495

496

497

498

499

500

501

502

503

504

505

506

507

508

509

510

511

512

513

514

515

516

517

518

519

520

521

522

523

524

525

526

527

528

529

530

531

532

533

534

535

Himmelmann A, Thevenin C, Harrison K, and Kehrl JH. 1996. Analysis of the Bruton's tyrosine kinase gene promoter reveals critical PU.1 and SP1 sites. Blood 87:10361044.

Ji P, Jayapal SR, and Lodish HF. 2008. Enucleation of cultured mouse fetal erythroblasts requires Rac GTPases and mDia2. Nat Cell Biol 10:314-321.

Kiyokawa H, Richon VM, Venta-Pérez G, Rifkind RA, and Marks PA. 1993. Hexamethylenebisacetamide-induced erythroleukemia cell differentiation involves modulation of events required for cell cycle progression through G1. Proc Natl Acad Sci U S A 90:6746-6750.

Kuehn HS, Radinger M, Brown JM, Ali K, Vanhaesebroeck B, Beaven MA, Metcalfe DD, and Gilfillan AM. 2010. Btk-dependent Rac activation and actin rearrangement following FcepsilonRI aggregation promotes enhanced chemotactic responses of mast cells. J Cell Sci 123:2576-2585.

Lane AA, and Chabner BA. 2009. Histone deacetylase inhibitors in cancer therapy.J Clin Oncol 27:5459-5468.

Lee HO, Davidson JM, and Duronio RJ. 2009. Endoreplication: polyploidy with purpose. Genes Dev 23:2461-2477.

Li LC, and Dahiya R. 2002. MethPrimer: designing primers for methylation PCRs. Bioinformatics 18:1427-1431.

Mattila PK, Batista FD, and Treanor B. 2016. Dynamics of the actin cytoskeleton mediates receptor cross talk: An emerging concept in tuning receptor signaling. J Cell Biol 212:267-280.

Moulding DA, Record J, Malinova D, and Thrasher AJ. 2013. Actin cytoskeletal defects in immunodeficiency. Immunol Rev 256:282-299.

Nowak D, Stewart D, and Koeffler HP. 2009. Differentiation therapy of leukemia: 3 decades of development. Blood 113:3655-3665.

Politz JC, Scalzo D, and Groudine M. 2013. Something silent this way forms: the functional organization of the repressive nuclear compartment. Annu Rev Cell Dev Biol 29:241270.

Raguz S, and Yague E. 2008. Resistance to chemotherapy: new treatments and novel insights into an old problem. Br J Cancer 99:387-391.

Rattray AM, and Muller B. 2012. The control of histone gene expression. Biochem Soc Trans 40:880-885.

Rebucci M, and Michiels C. 2013. Molecular aspects of cancer cell resistance to chemotherapy. Biochem Pharmacol 85:1219-1226.

Ruscetti SK. 1999. Deregulation of erythropoiesis by the Friend spleen focus-forming virus. Int J Biochem Cell Biol 31:1089-1109.

Schmidt U, van den Akker E, Parren-van Amelsvoort M, Litos G, de Bruijn M, Gutiérrez L, Hendriks RW, Ellmeier W, Lowenberg B, Beug H, and von Lindern M. 2004. Btk is required for an efficient response to erythropoietin and for SCF-controlled protection against TRAIL in erythroid progenitors. J Exp Med 199:785-795.

Schmittgen TD, and Livak KJ. 2008. Analyzing real-time PCR data by the comparative C(T) method. Nat Protoc 3:1101-1108.

Sharma S, Orlowski G, and Song W. 2009. Btk regulates B cell receptor-mediated antigen processing and presentation by controlling actin cytoskeleton dynamics in B cells. J Immunol 182:329-339. 
536 Storchova Z, and Pellman D. 2004. From polyploidy to aneuploidy, genome instability and cancer. Nat Rev Mol Cell Biol 5:45-54.

538 Talbert PB, and Henikoff S. 2010. Histone variants--ancient wrap artists of the epigenome. $539 \quad$ Nat Rev Mol Cell Biol 11:264-275.

540 Trapnell C, Roberts A, Goff L, Pertea G, Kim D, Kelley DR, Pimentel H, Salzberg SL, Rinn JL, 541 and Pachter L. 2012. Differential gene and transcript expression analysis of RNA-seq experiments with TopHat and Cufflinks. Nat Protoc 7:562-578.

Untergasser A, Cutcutache I, Koressaar T, Ye J, Faircloth BC, Remm M, and Rozen SG. 2012. Primer3--new capabilities and interfaces. Nucleic Acids Res 40:e115.

Vanegas N, García-Sacristán A, López-Fernández LA, Parraga M, del Mazo J, Hernández P, Schvartzman JB, and Krimer DB. 2003. Differential expression of Ran GTPase during HMBA-induced differentiation in murine erythroleukemia cells. Leuk Res 27:607615.

Ward J, Jr. 1963. Hierarchical grouping to optimize an objective function. . Journal of the American Statistical Association 8:236-244.

Zhao B, Mei Y, Schipma MJ, Roth EW, Bleher R, Rappoport JZ, Wickrema A, Yang J, and Ji P. 2016. Nuclear Condensation during Mouse Erythropoiesis Requires Caspase-3Mediated Nuclear Opening. Dev Cell 36:498-510.

554

555 


\section{Figure 1 (on next page)}

Differentially expressed genes between MEL and MEL-R cell lines.
A) Analysis of differentially expressed genes between MEL and MEL-R cell lines classified based on analysis of minimum variance (Ward 1963). B) Heat map zoomed to amplify the genes with higher fold-change values. Genes related to the actin cytoskeletal network are indicated by red asterisks. As expected, Sfpi/PU.1 presented strong differences in expression towards the progenitor cells and served as control for RNA-seq efficiency (green asterisk). C) Heat map limited to histone gene expression. The color scales shown in all maps illustrate the $\log _{10}$ FPKM. Red and blue colors represent high and low expression, respectively. 
B

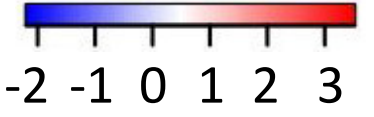

\section{Manuscript to be reviewed}

C
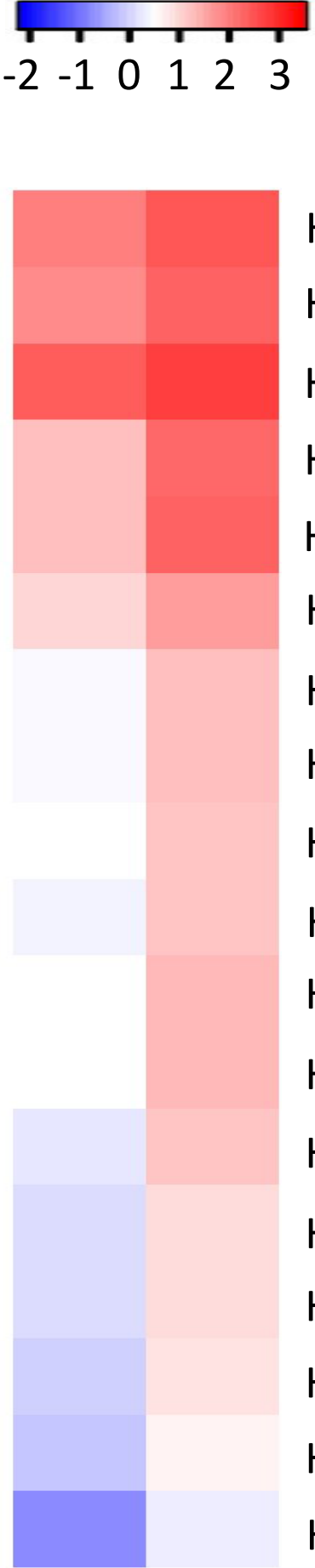

H2afx

Sfpi1*

Was*

Tmem176b

Aqp9

Al427809

Ncf2

Cd48

Rgs18

Ccdc88b

Siglec5

Tmem176a

Lgals3bp

Wdfy4*

Gpr128

Slc1a2

Dock2*

Csf2rb

Itgb2*

Rnase6

Oasl1

Nckap1l*

Il1rl1

Rin3

Zbtb8b

Cyth4

Il10ra

PId4

Plek*

Rac2*

Laptm5

Btk*

Rhag

1830077J02Rik

Fgd3*

Arhgef10l*

Slc25a45

Thy1*

Aff3

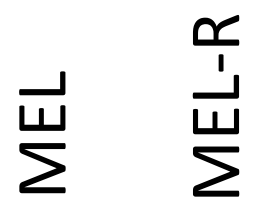

H1f0

$\mathrm{H} 3 \mathrm{f3b}$

Hist1h2bc

Hist1h1c

Hist2h2be

Hist1h2bj

Hist1h2bg

Hist2h2aa2

Hist1h2bn

Hist1h2bl

Hist1h2bk

Hist2h2aa1

Hist2h3c2

Hist1h2ba

Hist1h2bp

Hist3h2a

Hist1h1d

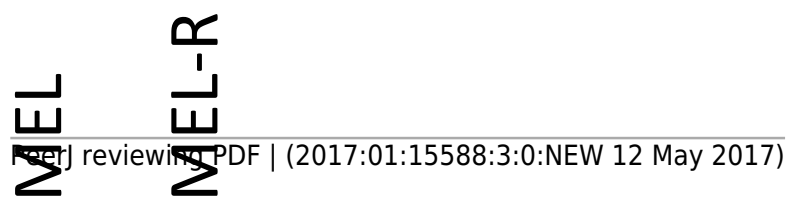


Figure 2 (on next page)

Tetraploidy characterizes HMBA-resistant cells.

DNA content (2C, 4C and $8 \mathrm{C}$ ) assayed by propidium iodide (PI) staining and flow cytometry show that B) HMBA induced differentiated MEL cells (MEL-96h) accumulate in G1 as compared with the A) uninduced cell line (MEL-Oh). C) DNA profile of HMBA-resistant cells (MEL-R) is similar to that observed in uninduced MEL cells regarding the fractions of cells in G1, S and G2-M. However, the DNA content profile is shifted to the right of the panel confirming that those cells become tetraploid. 

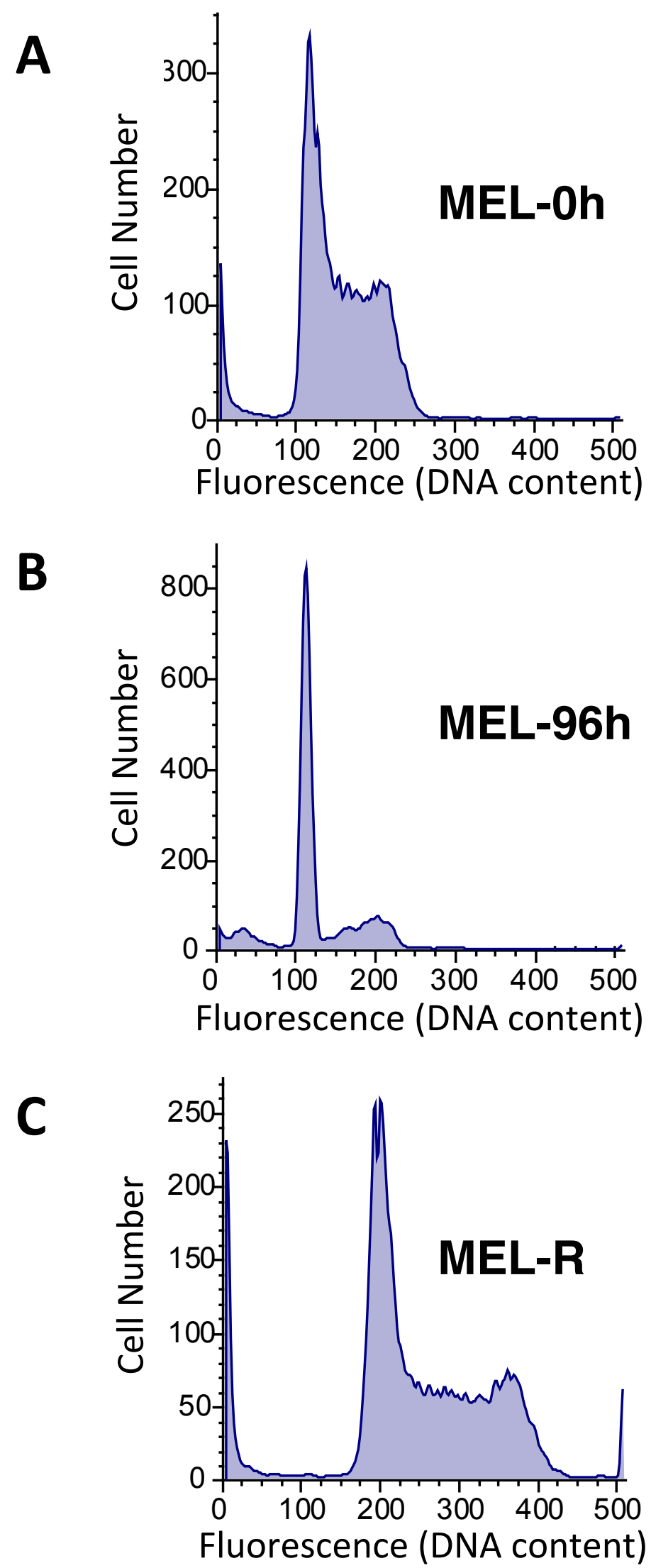

\section{C $4 \mathrm{C} \quad 8 \mathrm{C}$}


Figure 3 (on next page)

Validation of differentially regulated genes associated with the actin cytoskeletal network by qRT-PCR.

Selected genes that exhibited the highest FPKM values between MEL and MEL-R cell lines by RNA-seq were chosen for further validation by qRT-PCR. For the progenitor cell line, samples treated with HMBA for $96 \mathrm{~h}$ were also included. Data were normalized to $\beta$-actin expression for each sample. Bars represent \pm SD of triplicate determinations $(P<0.05)$. 

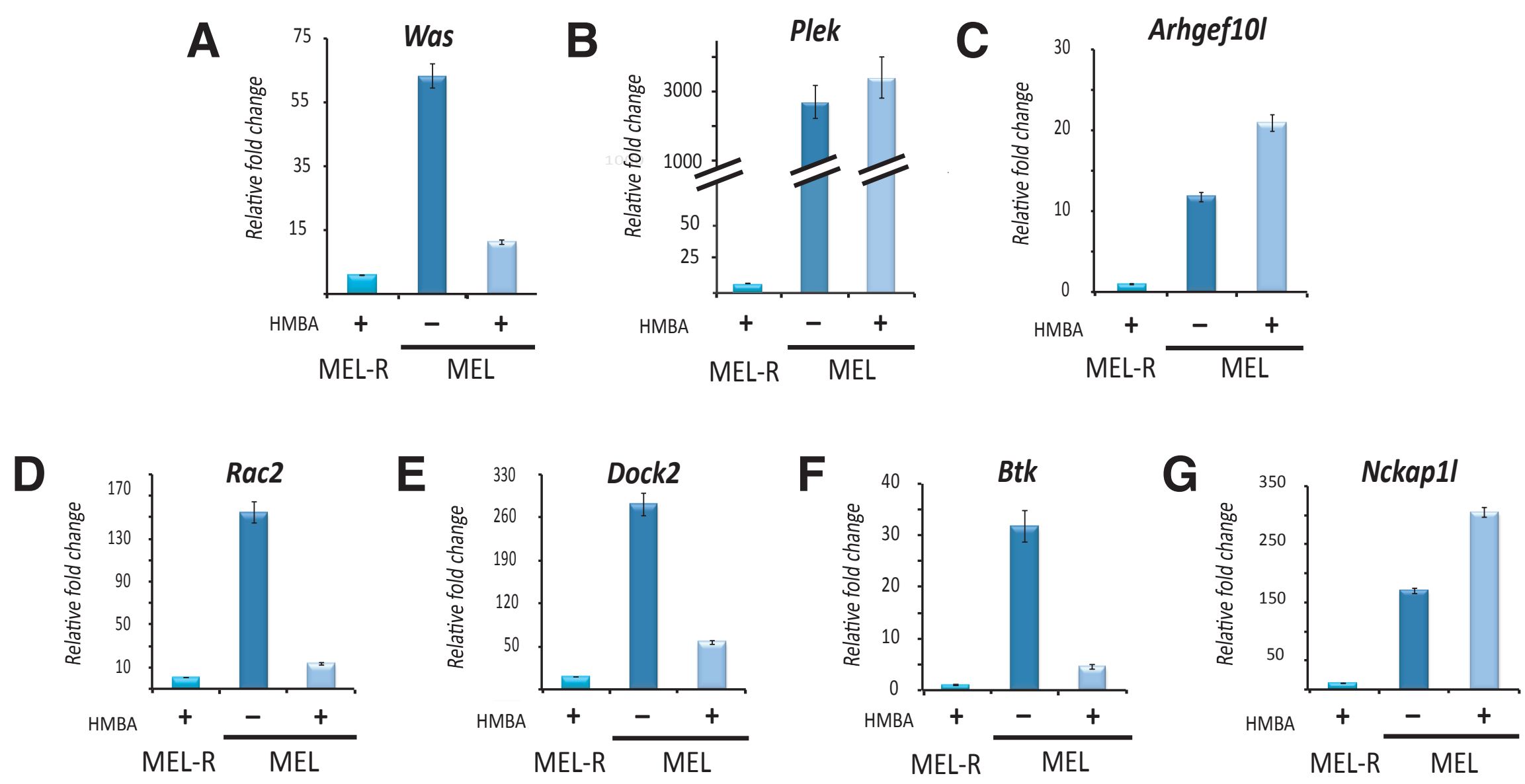
Figure 4 (on next page)

Differential histone gene expression between progenitor and resistant cell lines and after differentiation.

qRT-PCR analysis of histone genes, canonical and variant, up-regulated in A) MEL-R cells relative to MEL cells, and B) in HMBA-induced MEL cells (MEL 96h) relative to uninduced cells (MEL). Data were normalized to $\beta$-actin expression for each sample. Bars represent $\pm S D$ of triplicate determinations $(P<0.05)$. 
A

B
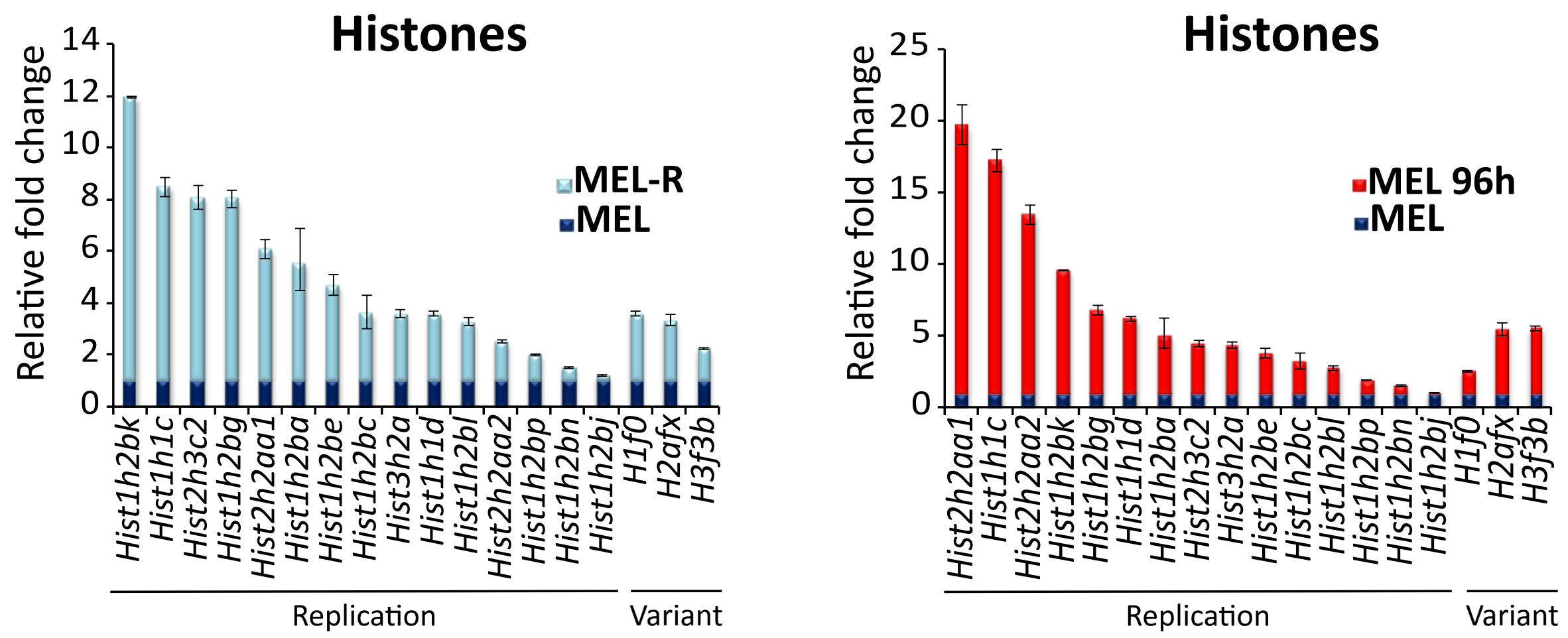
Figure 5 (on next page)

Methylation status of the Btk, Was and Plek promoters at the HMBA-resistant cells.

Genomic maps including exons (blue rectangles) and 5' and 3' UTRs (red rectangles) of A) Btk, B) Was and C) Plek. Expanded regions illustrate the promoter regions containing seven CpG islands (CG) for Btk and Was and five CpG islands for Plek. "Lollipop" schematic diagram of methylation patterns is represented below each sequence. Results from untreated (0h) or HMBA-treated MEL cells (96h) as well as MEL-R cells are shown. Black and white lollipops indicate methylated or unmethylated $\mathrm{CpGs}$, respectively, while undetermined methylation status (see text for details) is represented in yellow. 


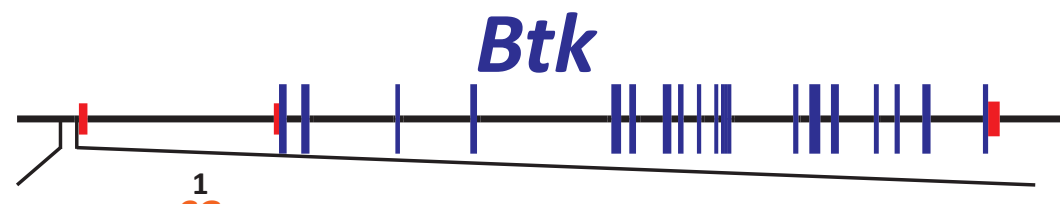

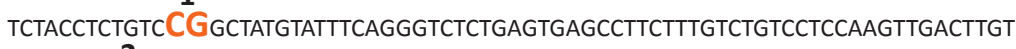
2

GTGATCCCG ATTCTCCCCTACTGAGGCCACAGGAGACCTTAAAGACACTGGCATCTCTCTTCTTCCTGTGCT 3 4 GATCGTCCCCCACAGTCCTTTAGGTACGTCATTCCTTTGCCCCAGAGAGGGTAGTCTGGTTATGACCTGTT GTTTGTTCAGCCCAGCCCCATCTTTTTAGGAGACTCAACCACCACCATAATGGGAAGAGTCTCTCAGAGCTG 5 GACTCTTGAGTGTAAAGAGGTCCCAGGCAAATGTCGGGGGGTGGGGGTAGAGAGTTGGGGGTGGGGA 6 GTGGAATAGGGACAGCAGCTCGAAATCAGATACCATATTGCTAAGGAGAAAAAAAAAAGGGCAATGGTT 7 TAAGTCAGGAAACAAAAAAGGGAACTGAGTGGCTGCGAAAGGG

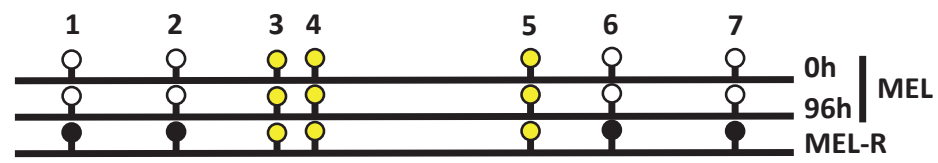

B

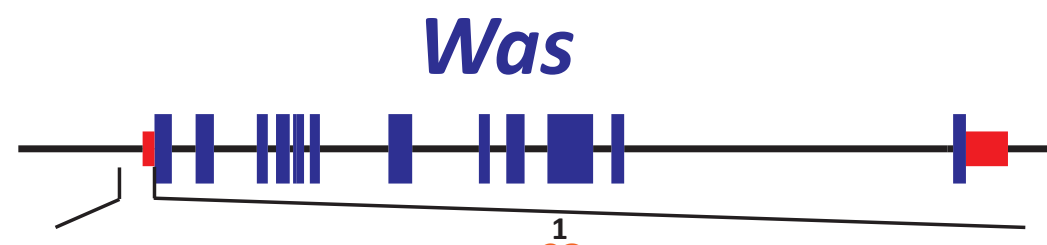

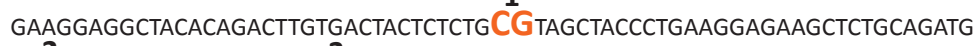
2 GCGTAGCTCTCCCTCAGTGTCCGACTAGAGCAAGGCTGATCTAAGCCTGTCAGAAGGAAATGGCCC 4 CGcacaAaAagggagaggaCGttgggaAgaAagaAgaAaggaAgatgccctgagctcattacaA ACTTGGATCTAGCCACGCAAATGGAGGAGGGCCCATGCCTGTCCTAGAGAGGAGAACAGGCCCTCT 7 GGGGGGCCCTGGAGGACTTATTTCCCTTGTGGTTTATTGTACTTCCTGTTCCCCTGCTCACTGCG GAA GTTCCTCTTCTTACCCTGCACCCAGAGCTTAGCTGGAGAGGACTAAGGCAGAAGGCAGCATGAATA
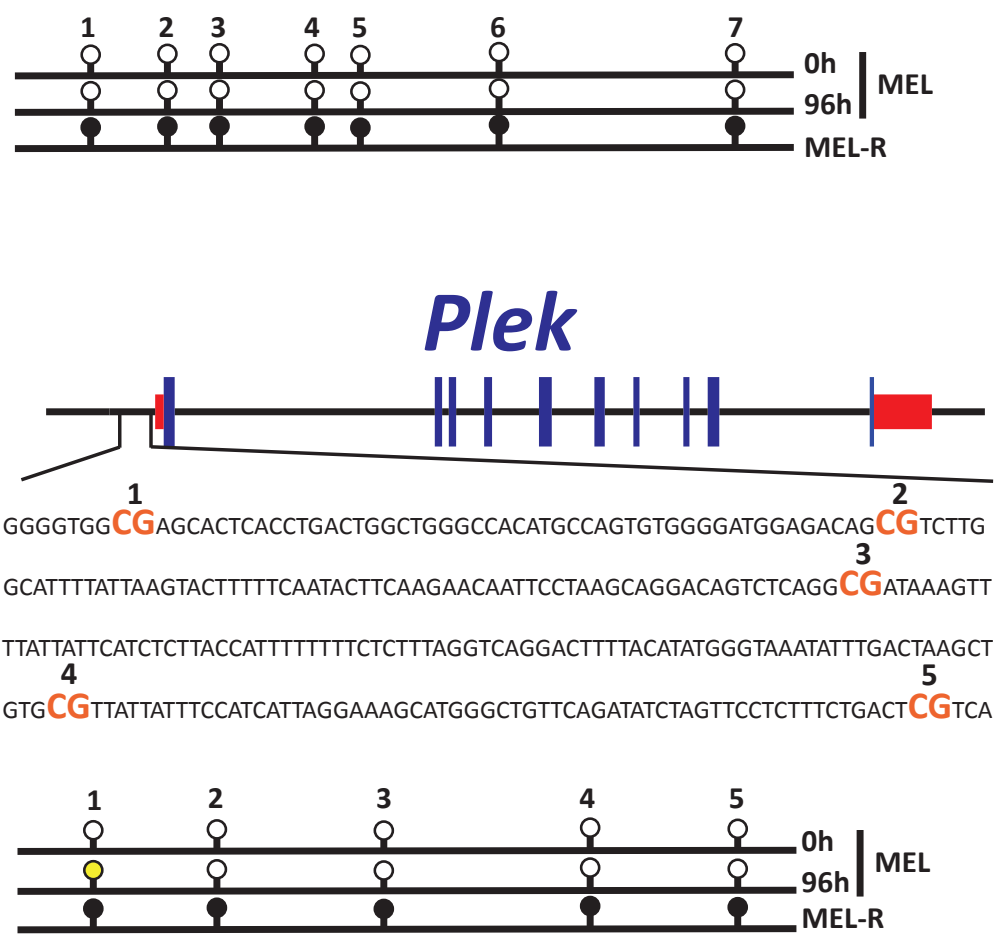
Figure $\mathbf{6}$ (on next page)

High and low expression of Dnmt1 and Tet3, respectively, are related to gene silencing and DNA methylation in MEL-R cells.

qRT-PCR was performed for Dnmt1, Dnmt3a and Dnmt3b methylases and Tet1, Tet2 and Tet3 demethylases in undifferentiated, HMBA-treated MEL cells and in MEL-R cells. Data were normalized to $\beta$-actin expression for each sample. Bars represent \pm SD of triplicate determinations $(P<0.05)$. 
A

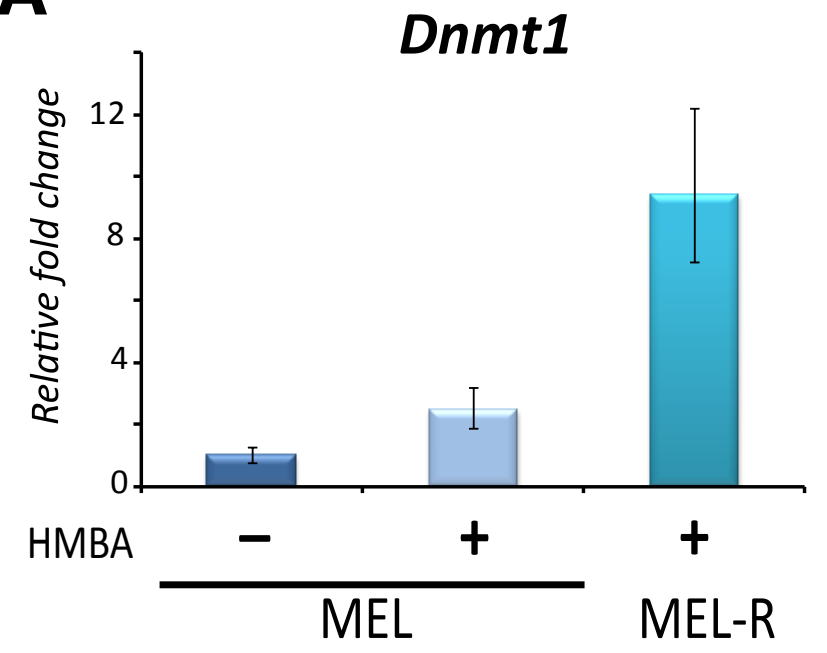

D

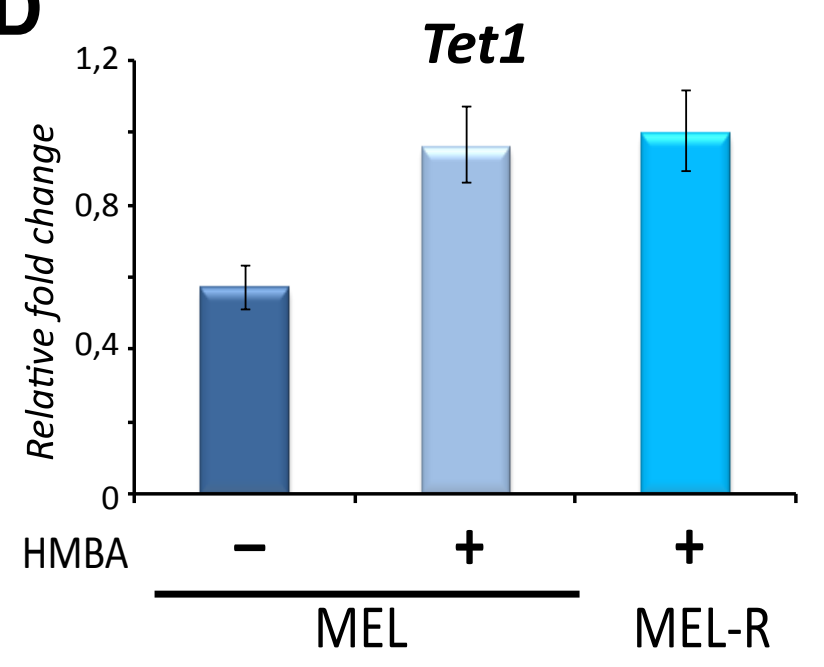

B

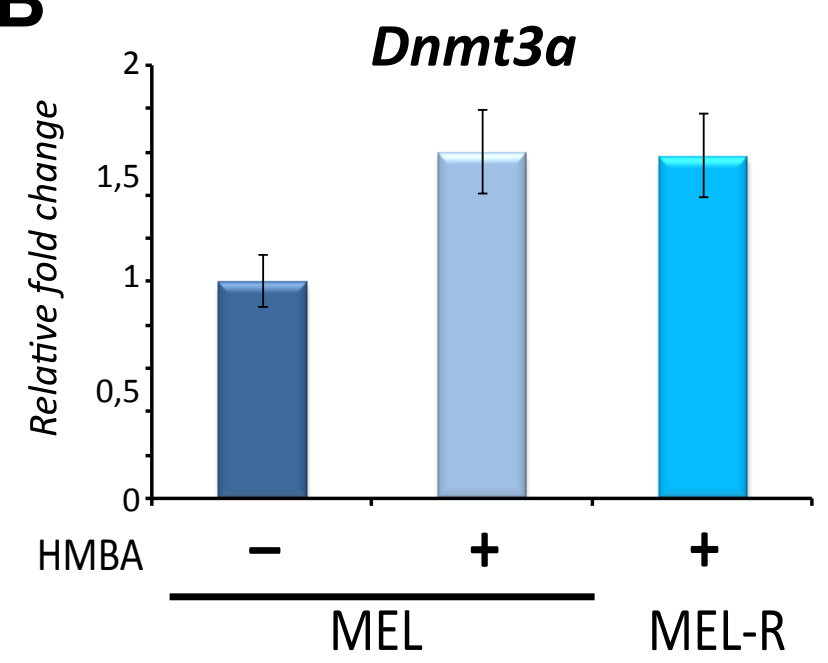

E

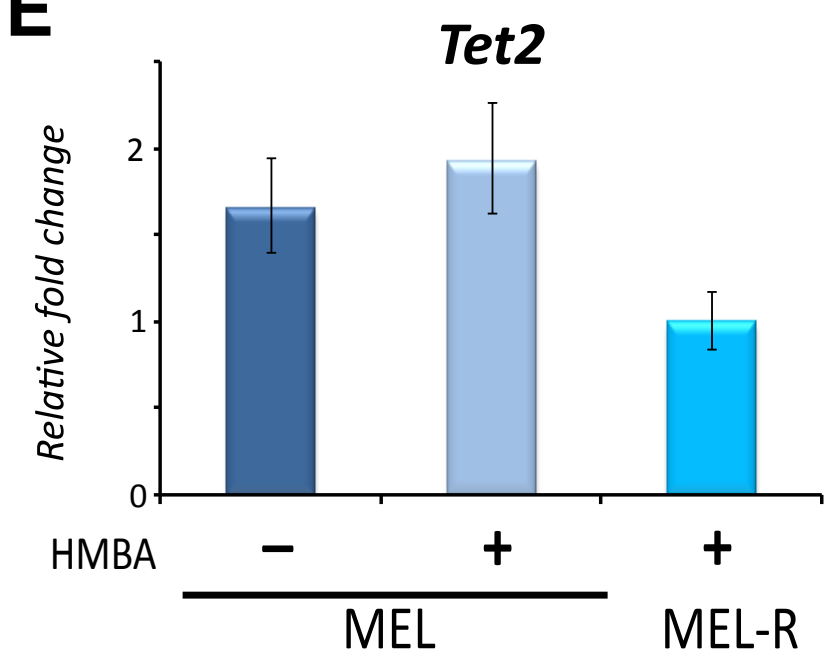

C
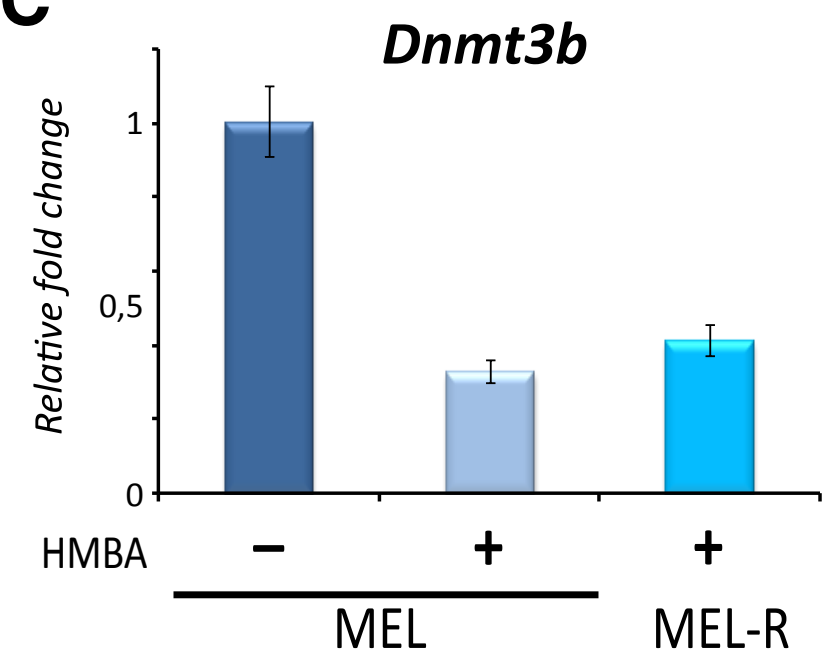

F

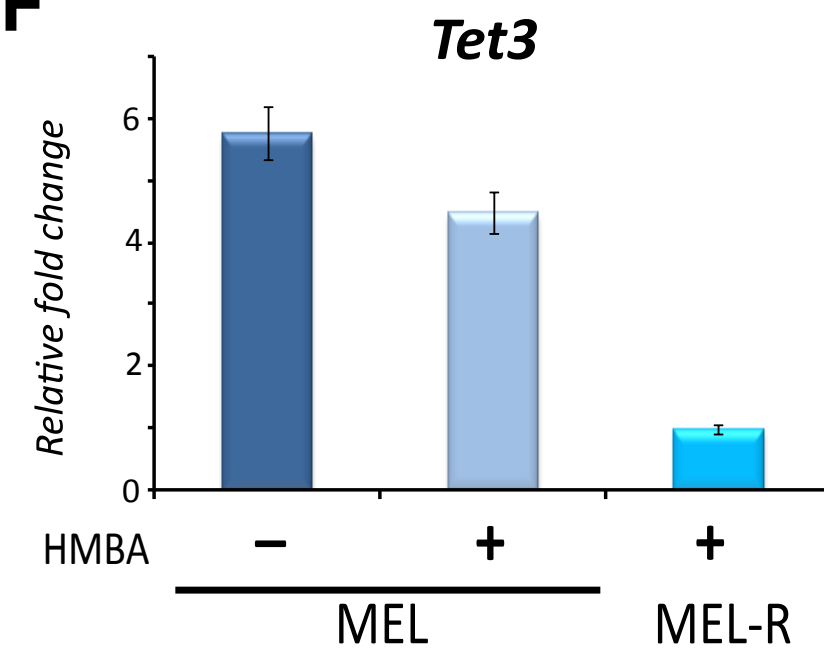


Figure 7 (on next page)

Actin protein is equally abundant in progenitor and resistant MEL cells.

Western blot analysis for actin protein expression in MEL and MEL-R leukemia cells and in 3T3 control fibroblasts. Equal amounts of protein were loaded and immunoblotted with an anti- $\beta$-actin antibody. Anti- $\alpha$-tubulin was used as a loading control. 


\section{T3 MEL MEL-R}

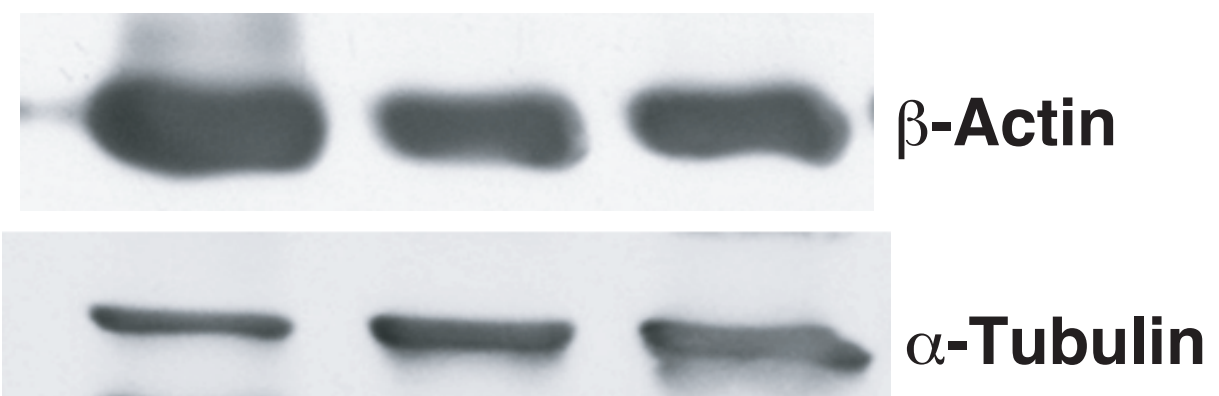




\section{Figure 8 (on next page)}

Actin cytoskeleton integrity is perturbed in MEL-resistant cell lines.

Confocal immunofluorescence microscopy of progenitor MEL cells and resistant MEL-R cells stained with a mouse monoclonal anti- $\beta$-actin antibody (red). Nuclear DNA was stained with DAPI (blue). Scale bar is $10 \mu \mathrm{m}$. 


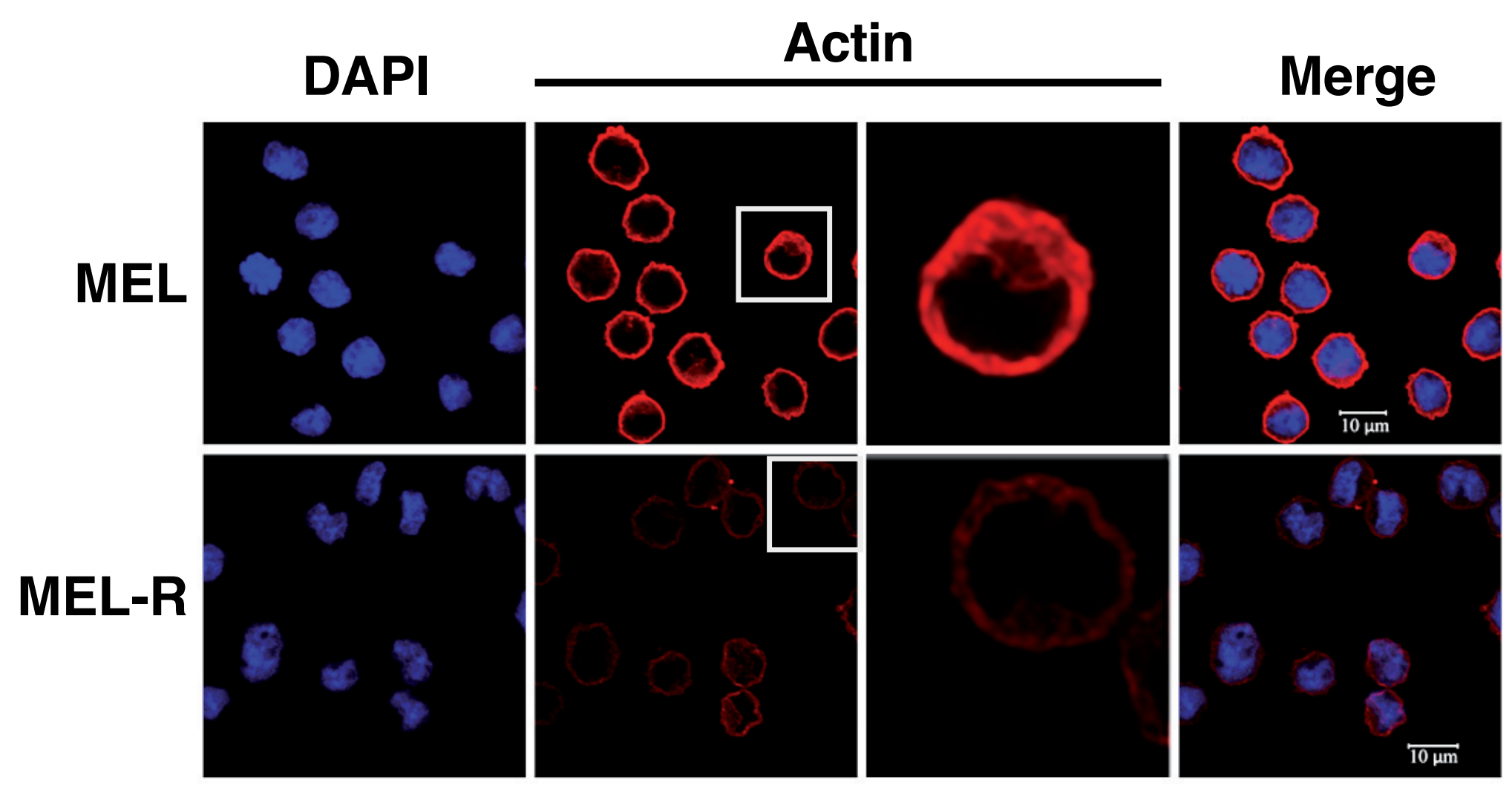




\section{Table 1 (on next page)}

List of differentially expressed genes related to actin cytoskeleton 
Table 1. List of differentially expressed genes related to actin cytoskeleton.

\begin{tabular}{|c|c|c|c|c|c|}
\hline Gene & Locus & FPKM_MEL & $\underset{\mathbf{R}}{\mathrm{FPKM} \text { MEEL }}$ & $\begin{array}{c}\text { Log2 } \\
\text { (Fold } \\
\text { Change) }\end{array}$ & $\begin{array}{c}\text { FDR- } \\
\text { adjusted } p- \\
\text { value }\end{array}$ \\
\hline${ }^{*}$ Plek & 11:16871208-16908721 & 90.85 & 0.06 & 10.56 & 0 \\
\hline${ }^{*} \operatorname{Rac2}$ & 15:78389598-78403213 & 91.00 & 0.09 & 9.93 & 0 \\
\hline *Dock2 & $11: 34126863-34414545$ & 23.21 & 0.03 & 9.74 & $1.08 \times 10^{-10}$ \\
\hline${ }^{*} B t k$ & $\begin{array}{c}X: 131076879- \\
131117679 \\
\end{array}$ & 149.00 & 0.36 & 8.70 & 0 \\
\hline $\operatorname{ltgb2}$ & 10:76993092-77028419 & 27.24 & 0.07 & 8.61 & 0 \\
\hline *Nckap1I & $\begin{array}{c}15: 103284255- \\
103329231\end{array}$ & 13.91 & 0.05 & 7.98 & 0 \\
\hline *Was & $X: 7658591-7667617$ & 65.48 & 0 & 6.03 & $1.08 \times 10^{-6}$ \\
\hline Wdfy4 & 14:33772732-33998252 & 9.78 & 0 & 3.29 & $5.65 \times 10^{-6}$ \\
\hline Fgd3 & $13: 49358478-49404577$ & 6.88 & 0 & 2.78 & $7.64 \times 10^{-4}$ \\
\hline${ }^{*}$ Arhgef10I & $\begin{array}{c}4: 140070399- \\
140221820 \\
\end{array}$ & 6.28 & 0 & 2.65 & $2.65 \times 10^{-3}$ \\
\hline Thy1 & $9: 43851466-43856662$ & 5.55 & 0 & 2.47 & $1.14 \times 10^{-2}$ \\
\hline
\end{tabular}

*Genes validated by RT-qPCR

* In order to avoid in the log2FC calculation an infinite magnitude leading to indeterminate numerical results, 
the $\log _{2}(1)$ is taken when the FPKM value is 0 . 